\title{
Cellular Distribution of Transforming Growth Factor- $\beta 1$ and Procollagen Types I, III, and IV Transcripts in Carbon Tetrachloride-induced Rat Liver Fibrosis
}

\author{
Harushige Nakatsukasa, Peter Nagy, Ritva P. Evarts, Chu-Chieh Hsia, Elizabeth Marsden, and Snorri S. Thorgeirsson
}

Laboratory of Experimental Carcinogenesis, National Cancer Institute, National Institutes of Health, Bethesda, Maryland 20892

\begin{abstract}
The cellular distribution and temporal expression of transcripts from transforming growth factor- $\beta 1$ (TGF- $\beta 1$ ) and procollagen $\alpha 1(\mathrm{I}), \alpha 1(\mathrm{III})$, and $\alpha 1(\mathrm{IV})$ genes were studied in carbon tetrachloride $\left(\mathrm{CCl}_{4}\right)$-induced rat liver fibrosis by using in situ hybridization technique. During the fibrotic process, TGF- $\beta 1$ and procollagen genes were similarly and predominantly expressed in Desmin-positive perisinusoidal cells (e.g., fat-storing cells and myofibroblasts) and fibroblasts and their expression continued to be higher than those observed in control rats. These transcripts were also observed in inflammatory cells mainly granulocytes and macrophage-like cells at the early stages of liver fibrosis. The production of extracellular matrix along small blood vessels and fibrous septa coincided with the expression of these genes. Expression of TGF- $\beta 1$ and procollagen genes were not detected in hepatocytes throughout the experiment. No significant differences in cellular distribution or time course of gene expressions among procollagen $\alpha 1(I), \alpha 1($ III), and $\alpha 1$ (IV) were observed. Desmin-positive perisinusoidal cells and fibroblasts appeared to play the principal role in synthesis of collagens in $\mathrm{CCl}_{4}$-induced hepatic fibrosis. The simultaneous expression of TGF- $\beta 1$ and procollagen genes in mesenchymal cells, including Desmin-positive perisinusoidal cells, during hepatic fibrosis suggests the possibility that TGF- $\beta 1$ may have an important role in the production of fibrosis. (J. Clin. Invest. 1990. 85:1833-1843.) TGF-B1 - collagens $•$ liver fibrosis • fat-storing cell • in situ hybridization
\end{abstract}

\section{Introduction}

Hepatic fibrosis is frequently observed after severe liver damage, and is also seen in connection with chronic liver diseases (1). Fibrogenesis is one of the most important process in the development of liver cirrhosis. The extracellular matrix of the liver is mainly composed of collagens, noncollagenous glycoproteins, and proteoglycans (2). The collagens are the major glycoproteins in the extracellular matrix, and are greatly increased in the cirrhotic liver (2). Chronic stimulation of relevant cells to produce extracellular matrix components is therefore a critical factor in the cirrhotic process. Furthermore, the extent of fibrogenesis correlates well with hepatic injury (3). Recurrent hepatic necrosis, inflammation, and regenerative

A preliminary report of this work appeared in 1988. (Hepatology 8:1303).

Address reprint requests to Dr. Thorgeirsson, National Cancer Institute, Building 37, Room 3C28, Bethesda, MD 20892.

Received for publication 8 June 1989 and in revised form 5 February 1990.

The Journal of Clinical Investigation, Inc.

Volume 85, June 1990, 1833-1843 process of the liver or some combination of these are also strongly related to the development of liver cirrhosis. However, the factor(s) which initiate(s) the gradual progression of cirrhosis is/are unknown.

Recently, transforming growth factor- $\beta$ (TGF- $\beta)^{1}$ has been found to regulate the production and degradation of certain extracellular matrix components $(4,5)$. The TGF- $\beta$ family has multifunctional action on fibroblasts and other cell types (6). TGF- $\beta 1$ increases the expression of collagen and fibronectin as well as increases the incorporation of these components into the matrix in cultured and transformed cells (4). In addition, TGF- $\beta 1$ inhibits collagenase expression, and also enhances the expression and secretion of tissue inhibitor of metalloproteinases together with certain growth factors (5). Therefore, TGF- $\beta 1$ may, under certain conditions, disturb the balance of synthesis and degradation of collagens and cause accumulation of extracellular matrix.

Since many cell types in the liver, such as perisinusoidal cells (e.g., fat-storing cells, myofibroblasts, etc.) (7-9), hepatocytes (10-12), and endothelial cells $(13,14)$, produce some components of extracellular matrix, the identity of the specific cell type(s) that produce collagens in hepatic fibrosis still remains controversial. Increased procollagen mRNA levels were found in the rat liver treated with $\mathrm{CCl}_{4}(15)$ or with dimethylnitrosamine (16) as well as in fibroblasts stimulated by a factor that is isolated from thioacetamide-induced fibrotic rat liver (17). However, the cellular distribution and extent of collagen gene expression and its time course in liver fibrosis are unknown.

The use of histochemical and immunohistochemical methods provides a powerful technique for identifying the components of the extracellular matrix. However, due to both the multicellular nature of the liver and the fact that both parenchymal and nonparenchymal liver cells are thought to be capable of producing extracellular matrix, this technique cannot reliably identify the cell type(s) that is predominant in synthesizing the components of the extracellular matrix during fibrogenesis. The in situ hybridization method is at present the most accurate procedure for evaluating the cellular distribution of gene expression in vivo. This method does not, however, address the role of posttranslational regulation or further processing of proteins such as intracellular degradation. Nevertheless, the in situ hybridization procedure provides an unambiguous identification of the cell type(s) expressing the genes of interests.

The aim of the present study was to define both temporal and cellular distribution of the expression of TGF- $\beta 1$ and type I, III, and IV collagen genes during the progression of rat hepatic fibrosis by using in situ hybridization technique. The

1. Abbreviations used in this paper: GAPDH, glyceraldehyde-3-phosphate dehydrogenase; GST-P, glutathione transferase-placental form; TGF- $\beta 1$, transforming growth factor- $\beta 1$. 

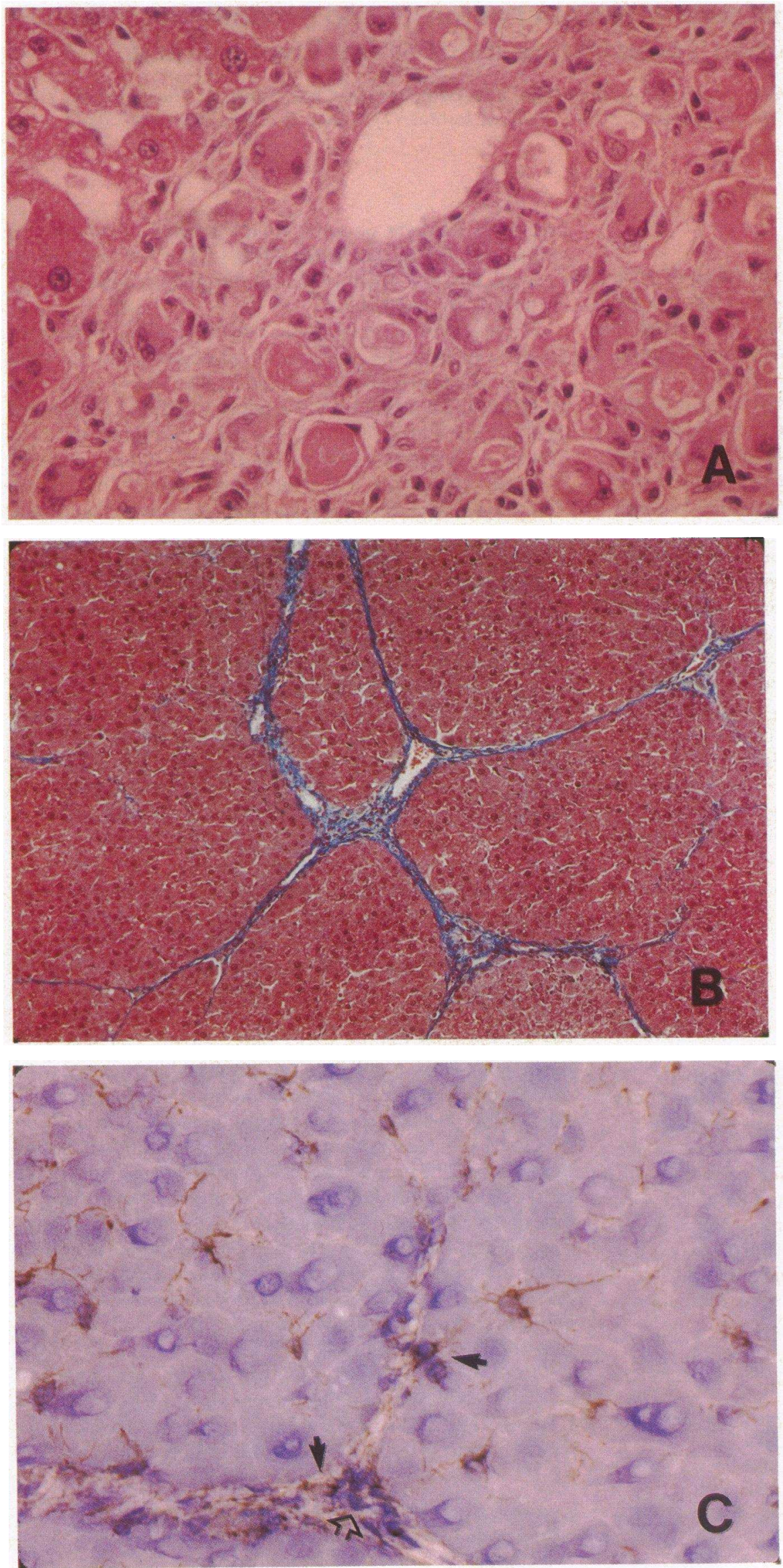

Figure 1. $(A)$ Centrilobular necrosis after $1 \mathrm{wk}$ of $\mathrm{CCl}_{4}$ treatment $(\mathrm{H} \& \mathrm{E}, \times 400)$. Proliferated mesenchymal cells and infiltrated inflammatory cells are present. Granulocytes and phagocyte giant cells are also observed. $(B)$ Early cirrhosis at $4 \mathrm{wk}$ (Masson's trichrome staining, $\times 100)$. (C) Immunohistochemistry $(\times 400)$ with Desmin antibody at 4 wk of $\mathrm{CCl}_{4}$ treatment. Fibrous septa composed of Desmin-positive perisinusoidal cells (arrow) and fibroblasts (open arrow). (D) Immunohistochemistry $(\times 400)$ with Vimentin antibody at 4 wk of $\mathrm{CCl}_{4}$ treatment. Most of the stromal cells are Vimentin positive which suggests fibroblasts. $(E)$ Advanced cirrhosis at 12 wk (Masson's trichrome staining, $\times 100$ ). 

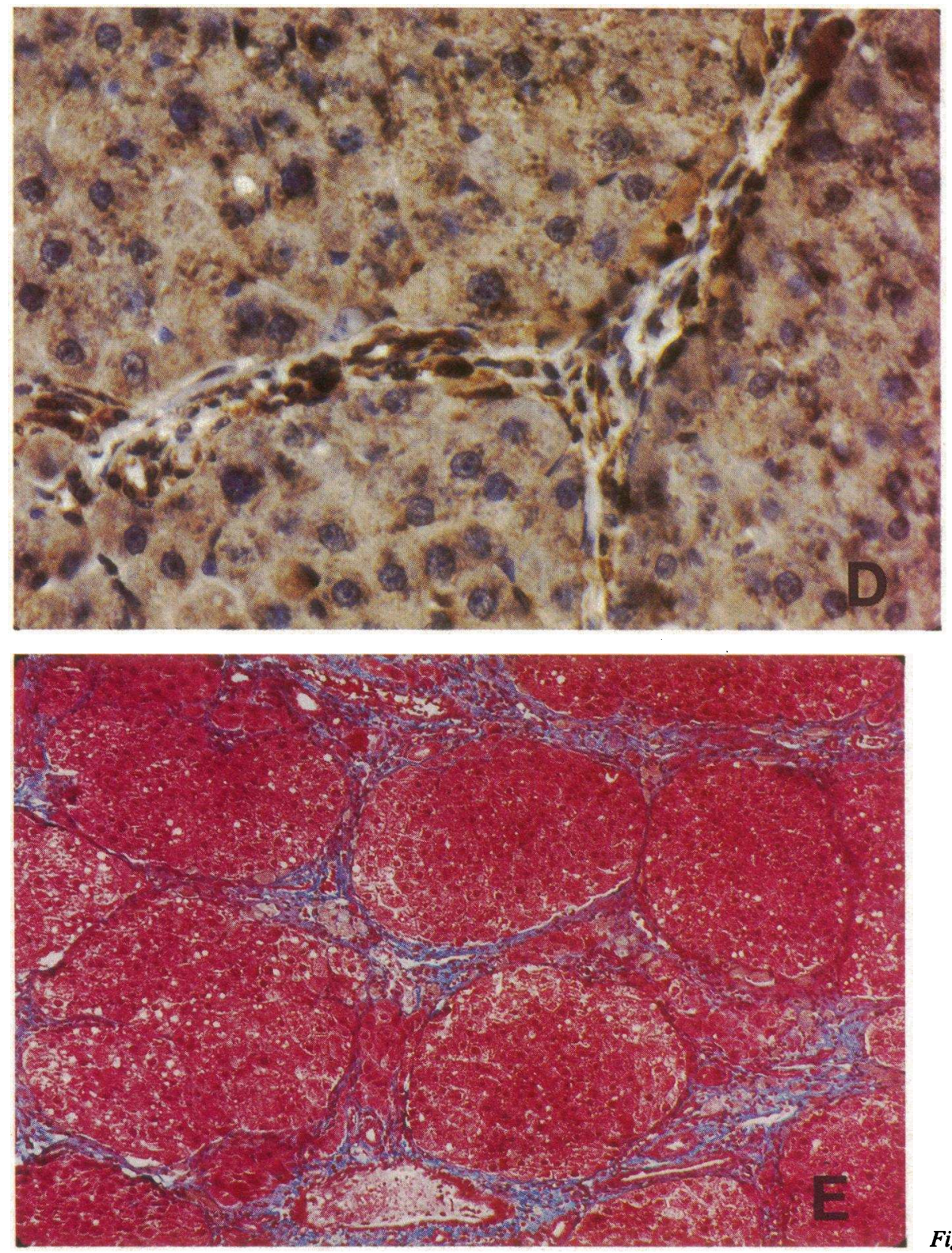

Figure 1 (Continued)

main focus was centered on answering two questions: which cell type is the predominant producer of collagens during hepatic fibrosis and what, if any, is the role of TGF- $\beta$ in the fibrotic process.

\section{Methods}

Treatment of animals. 67 Fischer male rats weighing $\sim 200 \mathrm{~g}$ were used. Throughout the experimental period all rats were fed standard Purina Chow pellets (NIH Supply) containing $0.05 \%$ phenobarbital (Sigma Chemical Co., St. Louis, MO) starting 1 wk before the administration of $0.33 \mathrm{ml} / \mathrm{kg}$ body wt of $\mathrm{CCl}_{4}$ (Fluka AG) once a week by gavage. Rats fed the same phenobarbital-containing pellet and received the same volume of saline instead of $\mathrm{CCl}_{4}$ were used as control. Rats were killed following a light anesthesia with ether by decapitation and exsanguinated from carotid arteries $1 \mathrm{wk}$ after the last administration of $\mathrm{CCl}_{4}$ at $1,2,4,6,8,10$, and $12 \mathrm{wk}$. In addition to the above animals, six normal rats without any treatment were also used.
The present experiments were undertaken according to the criteria of the National Institutes of Health for the care and use of laboratory animals in research.

Histological and immunohistochemical methods. Immediately after its removal, small pieces of the liver, which were not perfused, were frozen at $-50^{\circ} \mathrm{C}$ for in situ hybridization, and the residue was instantly frozen in liquid nitrogen and kept at $-70^{\circ} \mathrm{C}$. Frozen sections further fixed with aceton were used for desmin immunohistochemistry. Liver sections fixed with Bouin's fixative were used for vimentin immunohistochemistry and for hematoxylin and eosin. Masson's trichrome was used for demonstration of connective tissue.

Vectastain ABC Elite kit (Vector Laboratories, St. Louis, MO) was used for the identification of Desmin-positive perisinusoidal cells (e.g., fat-storing cells and myofibroblasts) (18) with Desmin antibody (Dako, Copenhagen, Denmark) and mesenchymal cells with antibodies raised against Vimentin (Boehringer-Mannheim, Indianapolis, IN).

Probes. The following probes were used in this study. A 600-bp fragment of the complementary deoxynucleic acid (cDNA) obtained from the fragment of $p \alpha 1 \mathrm{R} 2$ from rat procollagen $\alpha 1(\mathrm{I})$ (19), and an 1,800 -bp fragment from mouse procollagen $\alpha 1$ (III) (20) were generous 
gifts of Dr. B. Peterkofsky (National Cancer Institute, NIH) and were subcloned into the pGEM3z (Promega, Madison, WI). A 830-bp fragment of mouse procollagen $\alpha 1$ (IV) cDNA (21) subcloned into pGEM2 was a kind gift of Dr. Y. Yamada (National Institute of Dental Research, NIH). A 600-bp fragment from human TGF- $\beta 1$ cDNA subcloned into pGEM4 was kindly provided by Dr. G. I. Bell (22). Single stranded RNA probes of TGF- $\beta 1$ and procollagens were labeled with ${ }^{32} \mathrm{P}$ or ${ }^{35} \mathrm{~S}$ for Northern blot and in situ hybridization analyses, respectively, following the run off of the plasmid with the RNA polymerases. The cDNA for glyceraldehyde-3-phosphate dehydrogenase (GAPDH), which was kindly provided by Dr. C. Rories (National Cancer Institute), was used as internal standard for the Northern blot analyses (23). ${ }^{35} \mathrm{~S}$-labeled RNA probes were hydrolyzed to yield $\sim 0.3 \mathrm{~kb}$ fragments (24) before in situ hybridization. The specific activity of ${ }^{35} \mathrm{~S}$-labeled RNA probes was $1.9 \times 10^{9} \mathrm{dpm} / \mu \mathrm{g}$.

Northern blot analyses. Total RNA was isolated from the liver tissue by extraction in guanidine isothiocyanate and centrifugation in cesium chloride (25). Poly(A+)RNA was selected by oligo (dT)-cellulose chromatography (26). $10 \mu \mathrm{g}$ of poly(A+)RNA from each sample was separated in $1 \%$ agarose gel containing $2.2 \mathrm{M}$ formaldehyde (27), and transferred onto nitrocellulose. Blots were hybridized with ${ }^{32} \mathrm{P}$-labeled RNA probes at $60^{\circ} \mathrm{C}$ overnight. After high stringency washing ( $0.1 \%$ SDS and $0.1 \times$ SSC: $1.5 \mathrm{mM}$ sodium citrate, $15 \mathrm{mM} \mathrm{NaCl}, \mathrm{pH}$ 7.0 , at $70^{\circ} \mathrm{C}$, for $15 \mathrm{~min}$, three times) the blots were exposed to Kodak XAR film. The nitrocellulose filters were boiled for $10 \mathrm{~min}$ to strip off the radioactive probes, then rehybridized with ${ }^{32} \mathrm{P}$-labeled $\mathrm{CDNA}$ probe for GAPDH with the similar manner as RNA probes at $42^{\circ} \mathrm{C}$ and washed in high stringency condition for showing the internal standard.

In situ hybridization. In situ hybridization was performed with frozen liver sections with slight modification of our previous report (28). Briefly, paraformaldehyde fixed frozen liver sections were treated with $5 \mathrm{mM} \mathrm{MgCl}$ in PBS and $0.2 \mathrm{M}$ Tris ( $\mathrm{pH} 7.4$ ) containing $0.1 \mathrm{M}$ glycine for $10 \mathrm{~min}$. each. Then the liver sections were postfixed with 4\% paraformaldehyde in PBS for $20 \mathrm{~min}$. After rinsing with PBS, tissue sections were dehydrated in ethanol. The liver sections were prehybridized for $2 \mathrm{~h}$ at $48^{\circ} \mathrm{C}$ for procollagens and at $37^{\circ} \mathrm{C}$ for TGF- $\beta 1$. Hybridization was performed for 2-3 $\mathrm{h}$ at the same temperature as prehybridization using ${ }^{35} \mathrm{~S}$-labeled antisense RNA probes. This short hybridization time brought sufficient specific hybridization and avoided high nonspecific hybridization. Tissues were washed with 0.1 $\times$ SSC containing $50 \%$ formamide at $55^{\circ} \mathrm{C}$ for $1 \mathrm{~h}$, and were treated with ribonuclease A (50 $\mu \mathrm{g} / \mathrm{ml}$; Boehringer-Mannheim, FRG) and with ribonuclease $\mathrm{T} 1$ ( $250 \mathrm{U} / \mathrm{ml}$, Boehringer-Mannheim) for $1 \mathrm{~h}$ at $37^{\circ} \mathrm{C}$. After washing twice with $0.1 \times \mathrm{SSC}$ for $1 \mathrm{~h}$ the slides were dehydrated in ethanol and coated with Kodak NTB-2 emulsion. The exposure time was 2 wk at $4^{\circ} \mathrm{C}$. The slides were developed in Kodak D-19 developer and fixed in Kodak fixer and counterstained with hematoxylin and eosin. To rule out false-positive and -negative in situ hybridization, ${ }^{35} \mathrm{~S}$-labeled sense RNA probes for TGF- $\beta 1$ and procollagens as well as irrelevant antisense probes such as for rat albumin, alpha-fetoprotein and glutathione transferase-placental form (GST-P) were also examined in the same series of liver slides and under the identical conditions.

\section{Results}

Histology of the liver. Centrilobular necrosis of the liver with infiltrated inflammatory cells and proliferated mesenchymal cells was found following a single administration of $\mathrm{CCl}_{4}$ (Fig. $1 \mathrm{~A}$ ). Slight accumulation of fiber in the necrotic area, as demonstrated by Masson's trichrome, was already observed at this time. By week two, the presence of connective tissue became prominent at the necrotic central areas as well as in the portal tracts. Necrosis of the liver significantly decreased after this time point. The Desmin-positive perisinusoidal cells and fibroblasts were the predominant cell types in the fibrotic tissue.
After 2 wk, the connective tissue was increased and newly produced thin fibers were found by Masson's trichrome along some sinusoids or small blood vessels (including capillarized sinusoids). By week 4, accumulated connective tissues formed bridging fibrosis between central and portal area dividing the hepatic tissue into pseudolobules of different sizes (Fig. $1 \mathrm{~B}$ ), with Desmin-positive perisinusoidal cells and fibroblasts proliferating along the connective tissue (Fig. 1,C and D). A prominent liver cirrhosis was present at week 8 . By weeks 10 and 12 , a gradual increase in the extracellular matrix was observed along the borders of the pseudolobules (Fig. $1 E$ ). Livers from animals fed phenobarbital pellets and were not treated with $\mathrm{CCl}_{4}$ showed occasional single cell necrosis with macrophage infiltration and a slight increase in connective tissue around the portal tracts (data not shown).

Northern blot analyses. The expression of TGF- $\beta 1$ and procollagen $\alpha 1$ (I), $\alpha 1$ (III), and $\alpha 1$ (IV) was analyzed by Northern blot analyses. Results from TGF- $\beta 1$ and procollagen $\alpha 1$ (I) and $\alpha 1$ (III) are shown in Fig. 2. In the normal liver, procollagen $\alpha$ l(I) was very weak, whereas the transcripts for TGF- $\beta 1$ and procollagen $\alpha$ l(III) and $\alpha$ l(IV) (not shown) were detected. The mRNA levels of TGF- $\beta 1$ and procollagens in the fibrotic livers were higher than those observed in control animals. However, the expression of these genes varied from time to time. Similar variations of the procollagen gene expressions during the fibrotic process have also been observed by other investigators (15). In the livers of phenobarbital-treated rats, a slight increase in the expression of TGF- $\beta 1$ (not shown) and procollagen genes was observed, however, the expression of these genes remained at low level and somewhat varied throughout the experiment as seen in Fig. $2 B$. GAPDH expression was unchanged throughout the present experiments (Fig. $2 A$ ). Densitometric analysis of TGF- $\beta 1$ and $\alpha 1$ (III) (Fig. $2 A$ ) is documented in Table I after the standardization with the expression of GAPDH.

In situ hybridization. The distribution of TGF- $\beta 1$ and procollagen $\alpha 1$ (I), $\alpha 1$ (III), and $\alpha 1$ (IV) transcripts in normal liver was localized in mesothelial cells in the hepatic capsule, around the large blood vessels and periductal cells in the portal tracts, as well as around the central hepatic veins. Some sinusoidal-lining cells also weakly expressed these genes. No expression of TGF- $\beta 1$ and procollagen genes was observed in the hepatocytes.

The cellular distribution and time course of TGF- $\beta 1$, procollagen $\alpha$ l(I), $\alpha$ 1(III), and $\alpha$ l(IV) transcripts during the fibrotic process is shown in Fig. 3. Both the distribution and time course of gene expression of TGF- $\beta 1$ and procollagen $\alpha 1(\mathrm{I}), \alpha 1$ (III), and $\alpha 1$ (IV) were similar. By week 1 , these genes were expressed in the necrotic centrilobular areas mainly composed of Desmin-positive perisinusoidal cells, fibroblasts, and inflammatory cells, which are mainly granulocytes and macrophagelike cells (Fig. $4 A$ ). Various cells expressing these genes are present as a network surrounding the small groups or single necrotic hepatocytes. These genes were not expressed in hepatocytes. In addition, the expression of TGF- $\beta 1$ and procollagen genes was increased around the portal tract at this time. By week 2 , the area occupied by silver grains increased in size. The tracks of silver grains present in both central and portal areas, formed thin bridges before the accumulation of Masson's trichrome positive connective tissue. The connective tissue was mainly localized in the central and portal areas at this time, and did not form the bridging fibrosis. By week 4, silver 

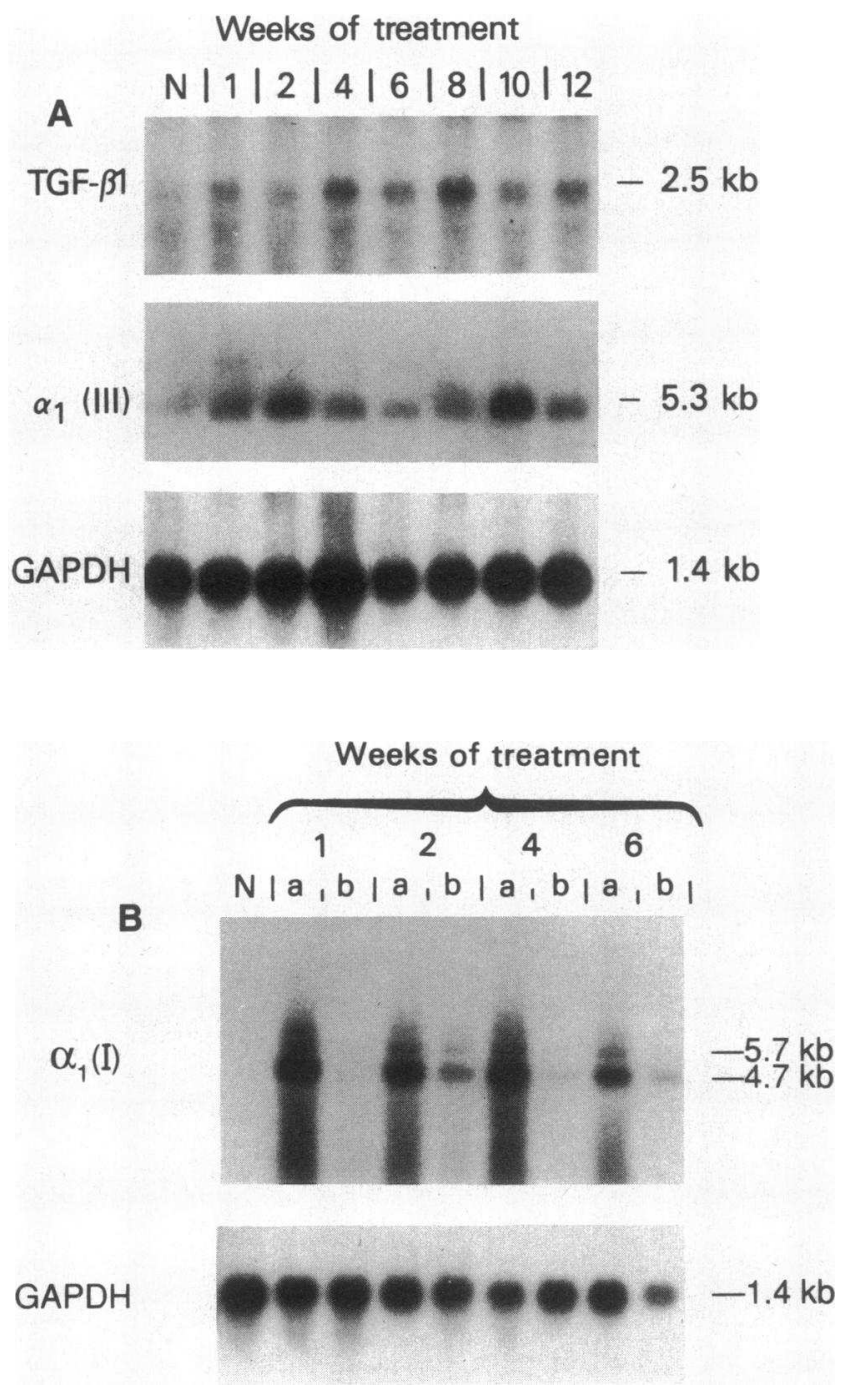

Figure 2. Northern blot analyses of TGF- $\beta 1$ and procollagen $\alpha 1$ (I) and $\alpha \mathrm{l}$ (III) during $\mathrm{CCl}_{4}$-induced fibrosis. $10 \mu \mathrm{g}$ of poly(A+)RNA was applied in each lane. Poly $(\mathrm{A}+) \mathrm{RNAs}$ were hybridized with ${ }^{32} \mathrm{P}-\mathrm{la}-$ beled RNA probes on the nitrocellulose filter. $(A)$ The expression of TGF- $\beta 1$ and procollagen $\alpha 1$ (III) genes increase following $\mathrm{CCl}_{4}$-treatment as compared to that of normal liver $(\mathrm{N})$. The expression of GAPDH, which was examined with cDNA probe, is unchanged throughout the experiments. (B) Procollagen $\alpha 1(\mathrm{I})$ gene expression in the liver of $\mathrm{CCl}_{4}$-treated $(a)$ and untreated $(b)$ (fed pellet with phenobarbital but not treated with $\mathrm{CCl}_{4}$ ) animals. Note the significant difference of transcript levels between $\mathrm{CCl}_{4}$-treated and untreated animals. The same finding was also observed during 8-12 wk (data not shown). A slight increase in the expression of procollagen $\alpha 1$ (I) gene is observed in phenobarbital-treated groups $(b)$ as compared to nor$\operatorname{mal}(N)$.

grains were found along the borders of the pseudolobules composed of mesenchymal cells and increased extracellular matrix (Fig. 3). The cell types expressing TGF- $\beta 1$ and procollagen genes along the sinusoids and small blood vessels, where the fibers accumulated, were mainly Desmin-positive perisinusoidal cells and fibroblasts as shown in Fig. $4, B$ and $C$. At later time points, the expression of these genes localized primarily in the fibrotic tissues and increased with the progression of fibrosis (not shown).
Table I. Relative Densitometric Analysis of TGF- $\beta 1$ and $\alpha 1$ (III) mRNA Levels

\begin{tabular}{lrrrrrrrr}
\hline \multicolumn{1}{c}{ Weeks } & $\mathrm{N}$ & 1 & 2 & 4 & 6 & 8 & 10 & 12 \\
\hline TGF- $\beta 1 / G A P D H$ & 1 & 2.1 & 1.5 & 2.7 & 1.4 & 5.0 & 2.2 & 2.7 \\
$\alpha 1$ (III)/GAPDH & 1 & 8.5 & 8.2 & 3.5 & 1.4 & 4.6 & 11.7 & 3.6
\end{tabular}

Density of TGF- $\beta 1$ and $\alpha 1$ (III) mRNA levels (Fig. $2 A$ ) were analyzed by using a computerized densitometry. Each density was standardized by relevant GAPDH level. Data were expressed relative density while standardized density of normal liver $(\mathrm{N})$ was set as 1 .

Transcripts for TGF- $\beta 1$ and procollagen genes were not detected in hepatocytes throughout the experiment. The expression of TGF- $\beta 1$ and the procollagen genes in some sinusoidal-lining cells was found in both normal and $\mathrm{CCl}_{4}$-treated animals. However, no increase in the expression of these genes in sinusoidal-lining cells in hepatic lobules was observed during the progression of fibrosis.

In order to rule out false-positive and -negative in these experiments, the sense probes for TGF- $\beta 1$, procollagen $\alpha 1$ (I), $\alpha$ l(III), and $\alpha$ l(IV) as well as the antisense RNA probes for rat albumin, alpha-fetoprotein, and glutathione transferase-placental form (GST-P) were used for in situ hybridization in the same series of liver slides and under identical conditions. The sense RNA probes slightly labeled nonspecifically but not significantly over the background (Fig. 5). The mRNA distributions for rat albumin (Fig. $6 \mathrm{~A}$ ), alpha-fetoprotein (Fig. $6 \mathrm{~B}$ ) and GST-P (Fig. $6 C$ ) probes were specific for the relevant mRNA and entirely different from those of TGF- $\beta 1$ and procollagens.

\section{Discussion}

In the present study, we have shown that the cellular distribution of TGF- $\beta 1$ and procollagen $\alpha 1$ (I), $\alpha 1$ (III), and $\alpha 1$ (IV) gene expressions was similar throughout the hepatic fibrogenesis. In the normal liver, the transcripts of TGF- $\beta 1$, and procollagen $\alpha 1$ (I), $\alpha 1$ (III), and $\alpha 1$ (IV) genes were observed in mesothelial cells in the hepatic capsule, around portal veins, periductal cells, and central hepatic veins as well as in sinusoidal-lining cells. At the early stages of the fibrotic process, mesenchymal cells principally Desmin-positive perisinusoidal cells, fibroblasts and inflammatory cells expressed procollagen genes together with the TGF- $\beta 1$ gene. In the later stages of fibrosis, the expression of these genes with the production of collagens and possibly other extracellular matrices was predominantly localized again in the same mesenchymal cell types. The expressions of TGF- $\beta 1$ and procollagen $\alpha 1$ (I), $\alpha 1$ (III), and $\alpha 1$ (IV) genes continued to be higher than those observed in control rats during the fibrotic process. Neither TGF- $\beta 1$ nor the procollagen gene expressions were observed in hepatocytes.

It has been found that certain types of collagens are synthesized by fat-storing cells by demonstrating the immunoreactivity of types I and III collagen in the rough endoplasmic reticuJum and Golgi's apparatus following carbon tetrachloride administration in rats (9). The present study provides evidence that strong expression of the most common procollagen genes is found in the mesenchymal cell compartment especially in 

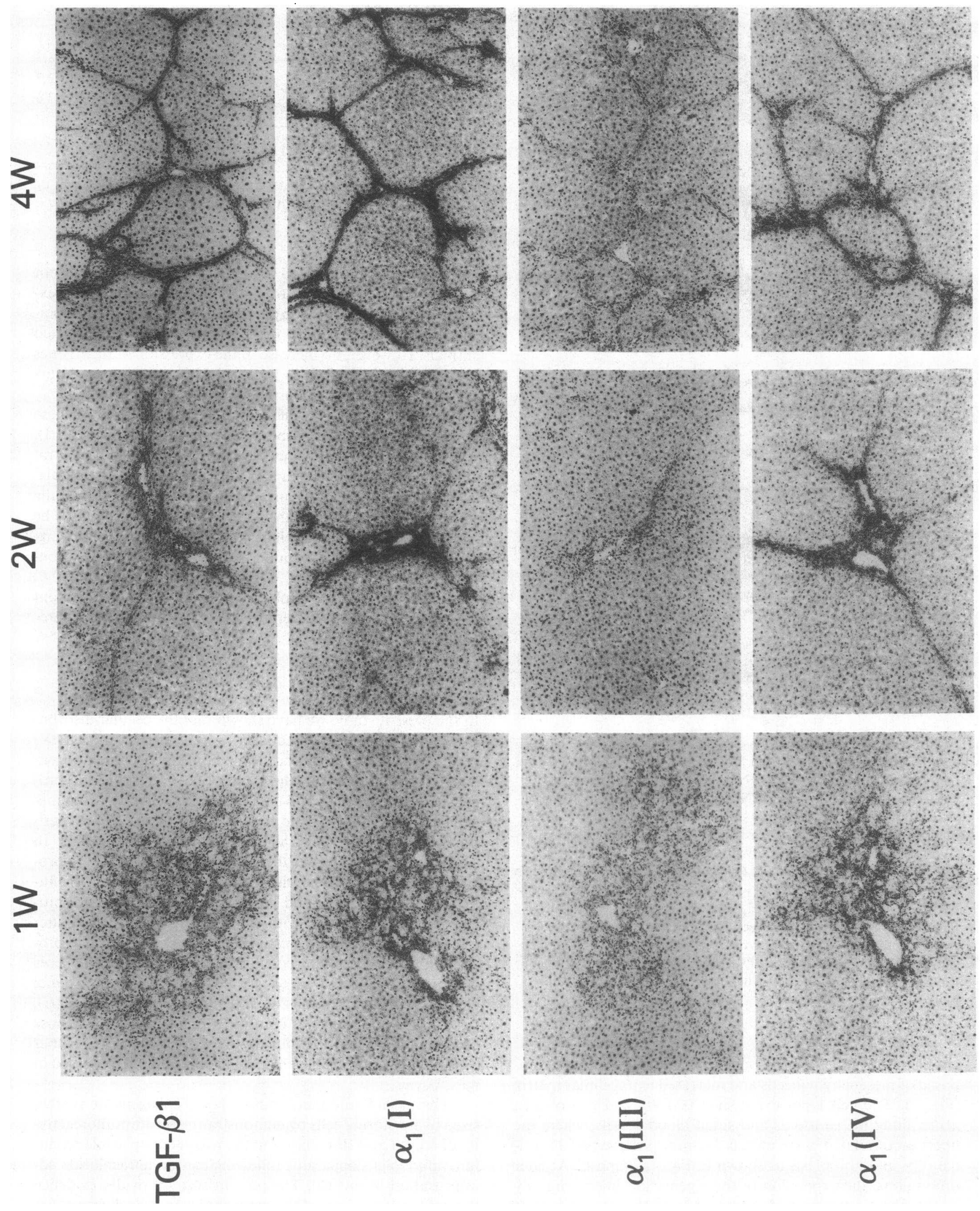

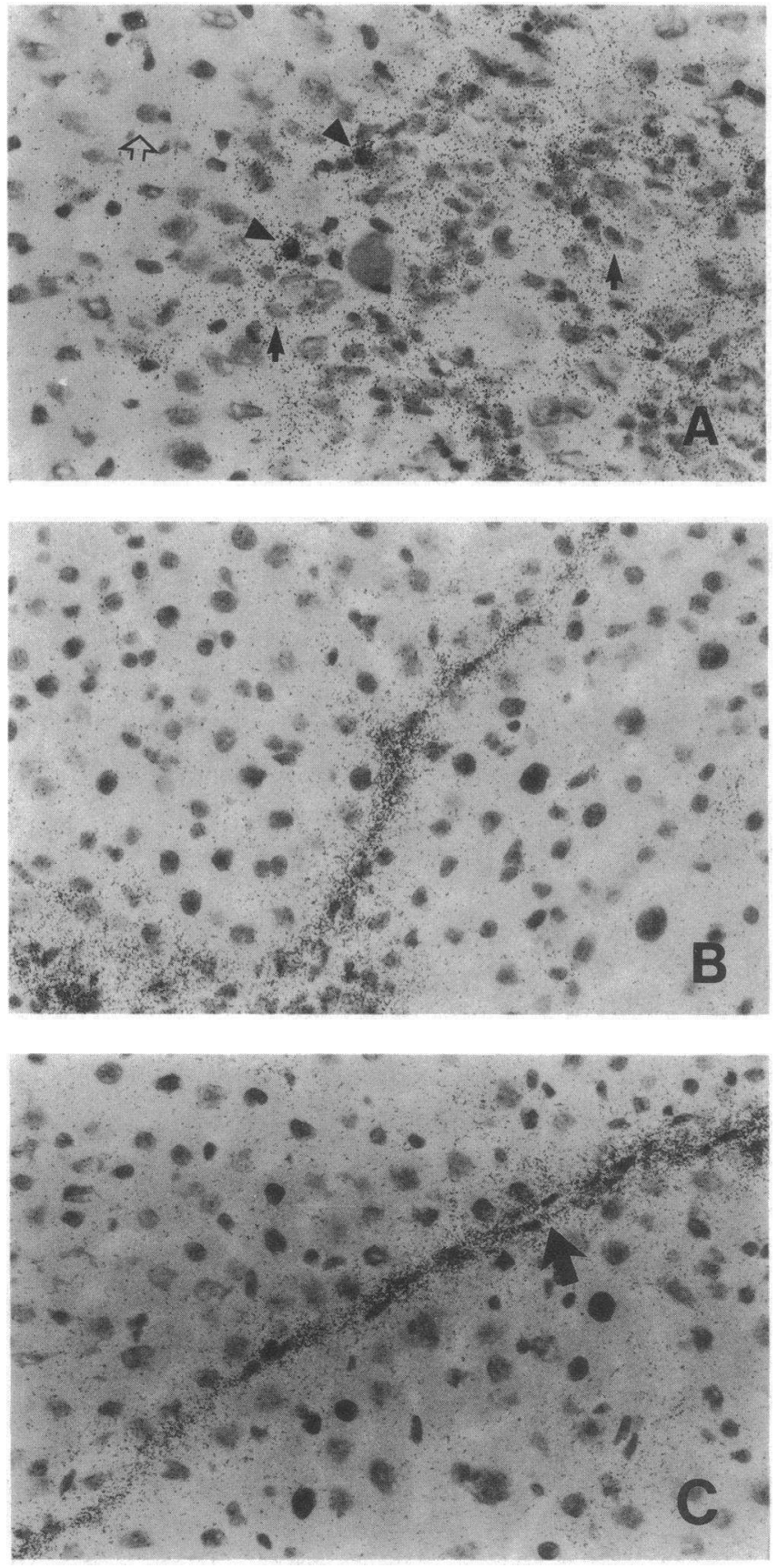

Figure 4. $(A)$ The distribution of TGF- $\beta 1$ transcripts in the inflammatory area at $1 \mathrm{wk}(\times 400)$. Silver grains are seen in perisinusoidal cells, fibroblastic cells (arrow) and in inflammatory cells (arrowhead). Hepatocytes (open arrow) are negative. See Fig. $1 A$ for reference. $(B)$ The distribution of procollagen $\alpha$ I(IV) transcripts at the front edge of the silver grain tracts at $4 \mathrm{wk}(\times 400)$. Silver grains are found mainly in the cells in the fibrous septa and along the sinusoidal space. $(C)$ Silver grains of TGF- $\beta 1$ transcripts by week 4 are also seen along the small blood vessels as indicated by a lumen (arrow) $(\times 400)$.
Desmin-positive perisinusoidal cells and fibroblasts simultaneously with an abundant production of extracellular matrix. These results indicate that the mesenchymal cell compartment plays the principal role in the $\mathrm{CCl}_{4}$-induced hepatic fibrogenesis. In contrast, the expression of TGF- $\beta 1$ and procollagen genes does not increase in the perisinusoidal cells locating in the hepatic lobules, in which no necrosis or accumulated connective tissues is observed, during the experiment. The involvement of other sinusoidal-lining cells, such as endothelial cells, Kupffer cells and pit cells in the fibrotic process is not clear at this point.

We and others have shown that hepatocytes can produce collagens and other extracellular matrix components in primary culture $(10,11)$. Also, it has been suggested, based on data obtained by immunohistochemical methods, that hepatocytes can produce types I, III, and IV collagens in human fibrotic livers, and basement membrane components in human chronic active liver diseases $(29,30)$. Martinez (31) reported that type I collagen as well as fibronectin were found in the rough endoplasmic reticulum of hepatocytes. Furthermore, Chojkier et al. reported that hepatocytes produce the majority of newly synthesized hepatic collagen in $\mathrm{CCl}_{4}$-induced rat liver fibrosis (12). Our data fail to demonstrate any significant increase over background in mRNA transcripts for TGF- $\beta 1$ and $\alpha 1$ (I), $\alpha 1$ (III), and $\alpha 1$ (IV) procollagen genes in hepatocytes from either normal liver or during $\mathrm{CCl}_{4}$-induced hepatic fibrosis. Pierce et al. (15) have shown that no significant increase in the DNA content of the liver takes place during $\mathrm{CCl}_{4}$-induced hepatic fibrosis strongly suggesting an increase per cell in procollagen synthesis. The data presented here, showing a selective increase in the steady-state level of the transcripts for the procollagen genes in the mesenchymal cell compartment, are in agreement with this conclusion. Milani et al. $(32,33)$ recently reported that by using in situ hybridization types I, III, and IV procollagen gene expressions were observed predominantly in nonparenchymal cells and concluded that hepatocytes do not appear to be significantly involved in procollagen production in $\mathrm{CCl}_{4}$-induced liver $\mathrm{fi}$ brosis. Our data are in good agreement with this. The disparity between our data and those of Martinez and Chojkier et al. is at present unclear. Nevertheless, the contribution of hepatocytes to the increase in collagen during $\mathrm{CCl}_{4}$-induced hepatic fibrosis is at best questionable.

The distribution of type I, III, and IV collagens is different, since type I and III collagens are the main components of interstitial collagens, whereas type IV collagen is one of the main components of basement membrane $(2,31)$. However, the cellular distribution and the time course of the expression of procollagen $\alpha 1$ (I), $\alpha 1$ (III), and $\alpha 1$ (IV) genes were very similar throughout the experiment. Procollagen genes as well as TGF- $\beta 1$ gene are all similarly and simultaneously expressed in the necrotic area in the early stages. In the later stages, they are expressed along the small blood vessels and the fibrous septa. The expression of these genes is associated with the increase in the number of Desmin-positive perisinusoidal cells and fibro-

Figure 3. The cellular distribution and the time course of TGF- $\beta 1$, procollagen $\alpha 1$ (I), $\alpha 1$ (III), and $\alpha 1$ (IV) transcripts at 1,2 , and 4 wk of CCl treatment $(\times 100)$. TGF- $\beta 1$ and procollagen genes are all similarly expressed during fibrotic process. At 1 wk, silver grains are found in the centrilobular area where necrosis, inflammation, and regeneration are observed. At 2 wk, the tracks of silver grains in both central and portal area form bridges. At $4 \mathrm{wk}$, silver grains are found primarily in the cells in fibrous septa and increased with the progression of fibrosis. 

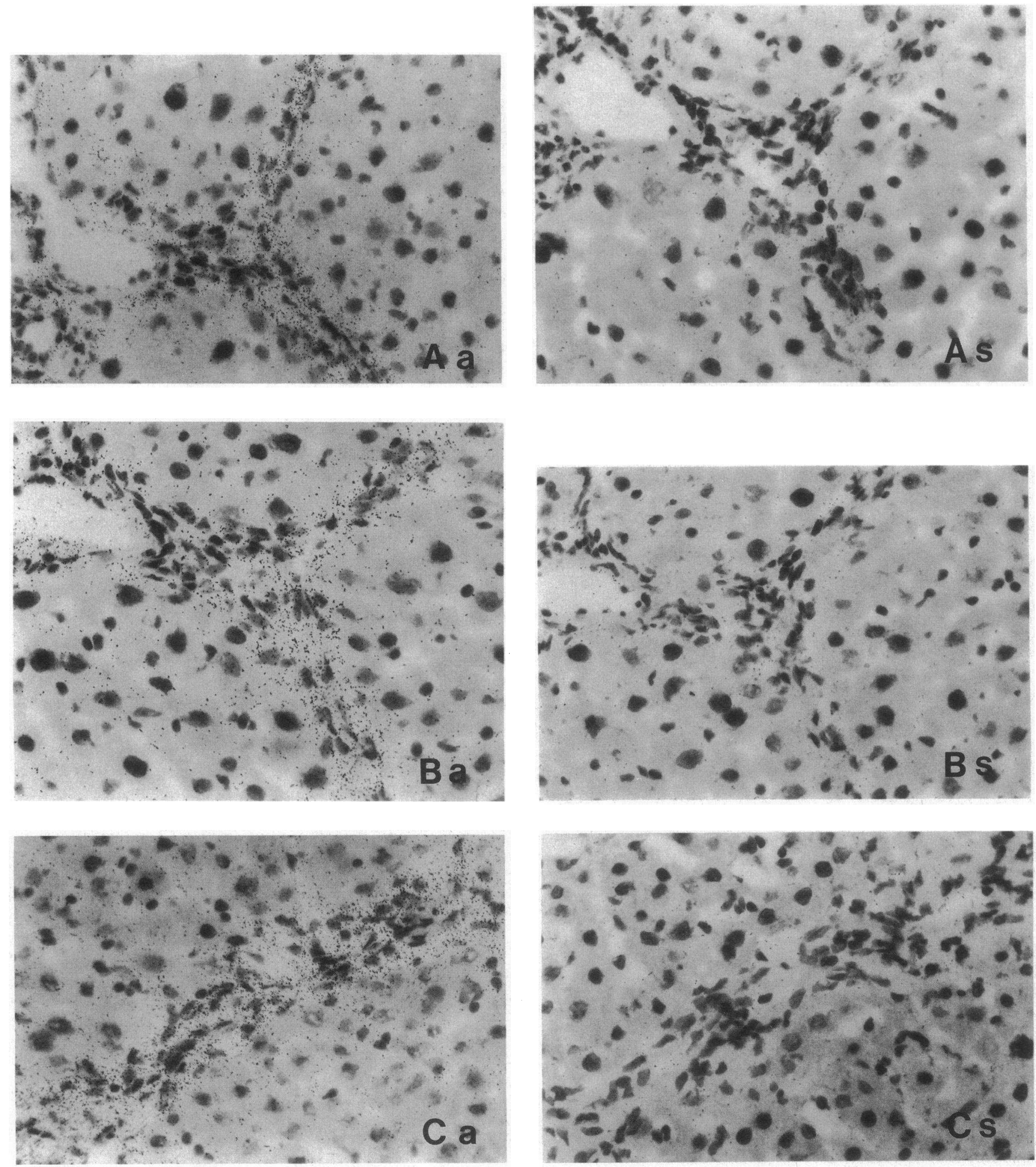

Figure 5. In situ hybridization with antisense (a) and sense (s) RNA probes for TGF- $\beta 1(A)$, procollagen $\alpha 1(\mathrm{I})(B), \alpha 1(\mathrm{III})(C)$, and $\alpha 1(\mathrm{IV})(D)$. Silver grains from antisense probes are observed in the fibrous septa and along the sinusoids, whereas the density of grains from the sense probes is not significantly different from nonspecific background level $\left(\mathrm{CCl}_{4} 8 \mathrm{wk}, \times 400\right)$.

blasts along the connective tissue, and coincides with the production of extracellular matrix. Although the cellular distribution and time course of procollagen $\alpha$ (III) expression were similar to other procollagens and TGF- $\beta 1$, the number of silver grains per cell of procollagen $\alpha 1$ (III) was smaller than others as shown in Fig. 3. The reason for this difference is not clear, however, one could speculate that the transcription level or the stability of procollagen $\alpha 1$ (III) mRNA might be differ- 

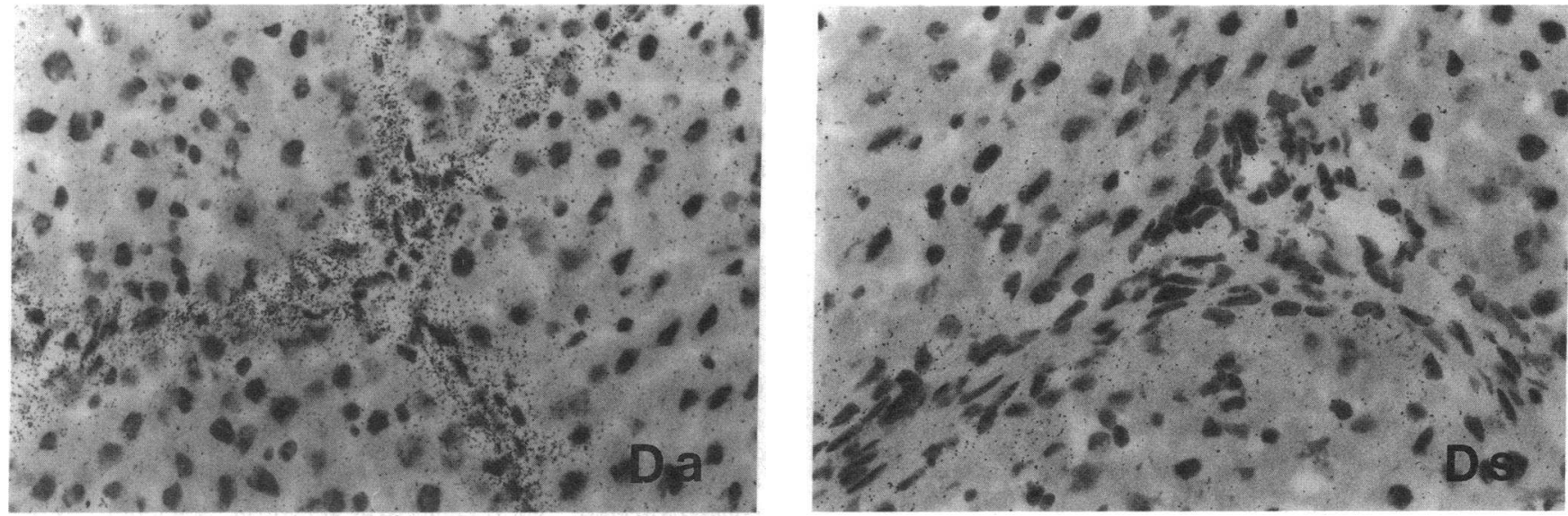

Figure 5 (Continued)

ent from the other procollagen genes as suggested by Pierce et al. (15).

TGF- $\beta$ has been shown to be both chemotactic for fibroblasts and also able to greatly enhance synthesis of the extracellular matrix components by these cells $(6,34)$. TGF- $\beta$ stimulates the proliferation of fibroblasts and small vessels (35), as well as increases the collagen synthesis of human dermal fibro-
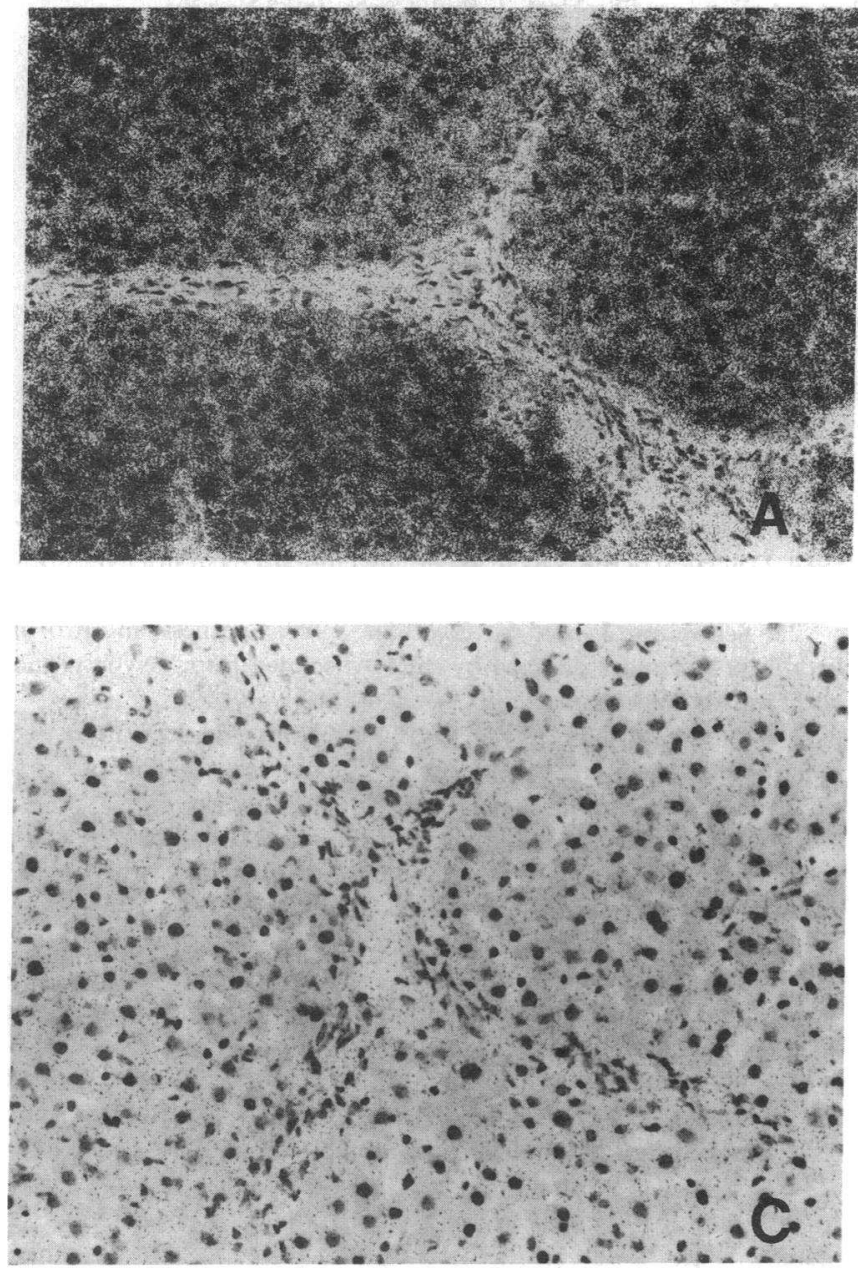

blasts (36). The increased mRNA level and production of both collagens and fibronectin by TGF- $\beta$ are found in fibroblasts obtained from mouse, rat and human (36-38). TGF- $\beta$ also causes marked increase in proline and leucine incorporation into collagens (35). In addition, TGF- $\beta$ inhibits the expression of tissue collagenase, which is a specific enzyme for degradation of mammalian interstitial collagens, and enhances the

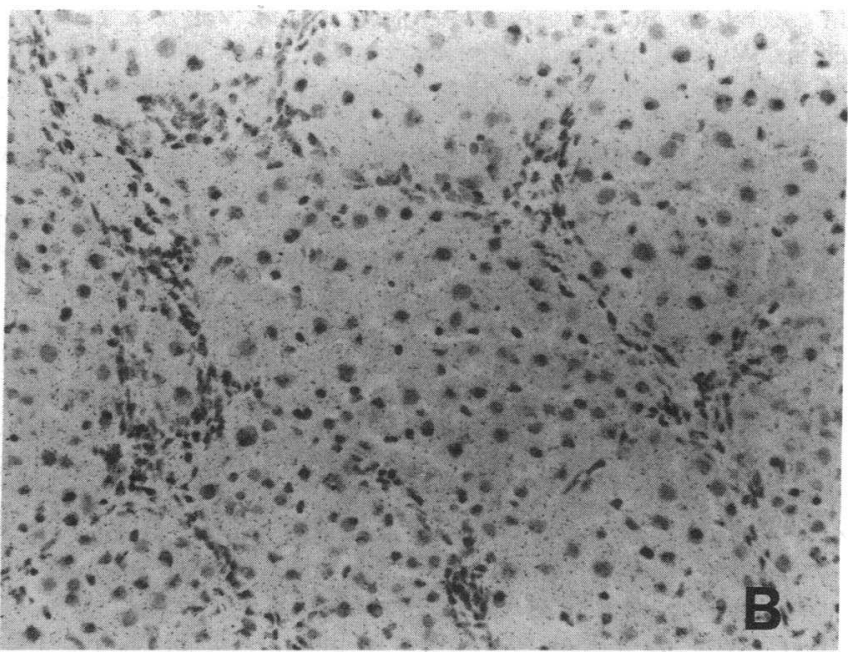

Figure 6. In situ hybridization with irrelevant antisense RNA probes in fibrotic liver $\left(\mathrm{CCl}_{4} 8 \mathrm{wk}, \times 200\right)$. Transcripts of rat albumin $(A)$ are observed only in hepatocytes but not in stromal cells. Alpha-feto protein $(B)$ is not significantly expressed in fibrotic liver. GST-P $(C)$ transcripts are observed only in bile duct cells (not shown) but not in hepatocytes or stromal cells. 
production of tissue inhibitor of metalloproteases, which inhibits the collagenase activity (5). Thus TGF- $\beta$ is capable of stimulating fibrogenesis by the fibroblast. Furthermore, it was recently suggested in an abstract that TGF- $\beta$ may play a role in the hepatic fibrogenesis through its effect on fat-storing cell collagen synthesis, because of the observation that cultured fat-storing cells contained significant amount of mRNA of both TGF- $\beta 1$ and type I procollagen and these mRNA levels were increased by TGF- $\beta$ treatment (39). In the present study, TGF- $\beta 1$ gene is strongly expressed not only in the Desminpositive perisinusoidal cells but also in fibroblasts and inflammatory cells together with the expression of procollagen genes in the same cell types throughout the progression of fibrosis. It is therefore possible that TGF- $\beta 1$ may have enhanced both proliferation and collagen synthesis in the mesenchymal cells by autocrine and paracrine mechanisms resulting in excess accumulation of connective tissue throughout the fibrotic process in the liver.

\section{Acknowledgments}

Authors thank A. Olson for densitometric analyses. F. Williams and N. Higgins are also acknowledged for secretarial expertise.

\section{References}

1. Galambos, J. T. 1985. Alcoholic cirrhosis (in relation to cirrhosis in general). In Bockus Gastroenterology. 4th ed. Vol. 5. J. E. Berk, editor. W. B. Saunders Co., Philadelphia, PA. 3012-3049.

2. Rojkind, M., and R. Perez-Tamayo. 1983. Liver fibrosis. Int. Rev. Connect. Tissue Res. 10:333-393.

3. Reubner, B. H. 1986. Collagen formation and cirrhosis. Semin. Liver Dis. 6:212-220.

4. Ignotz, R. A., and J. Massague. 1986. Transforming growth factor $-\beta$ stimulates the expression of fibronectin and collagen and their incorporation into the extra-cellular matrix. J. Biol. Chem. 261:43374345.

5. Edwards, D. R., G. Murphy, J. J. Reynolds, S. E. Whitham, A. J. P. Docherty, P. Angel, and J. K. Heath. 1987. Transforming growth factor beta modulates the expression of collagenase and metalloproteinase inhibitor. EMBO (Eur. Mol. Biol. Organ.) J. 6:18991904.

6. Roberts, A. B., N. L. Thompson, U. Heine, C. Flanders, and M. B. Sporn. 1988. Transforming growth factor $\beta$ : possible roles in carcinogenesis. Br. J. Cancer. 57:594-600.

7. Kent, G., S. Gay, T. Inoyue, R. Bahu, O. T. Minick, and H. Popper. 1976. Vitamin A-containing lipocytes and formation of type III collagen in liver injury. Proc. Natl. Acad. Sci. USA. 73:3719-3722.

8. Friedman, S. L., F. J. Roll, J. Boyles, and M. Bissell. 1985. Hepatic lipocytes: the principal collagen-producing cells of normal rat liver. Proc. Natl. Acad. Sci. USA. 82:8681-8685.

9. Takahara, T., T. Kojima, C. Miyabayashi, K. Inoue, H. Sakai, Y. Muragaki, and A. Ooshima. 1988. Collagen production in fat-storing cells after carbon tetrachloride intoxication in the rat. Lab. Invest. 59:509-521.

10. Diegelmann, R. F., P. S. Cuzelian, R. Gay, and S. Gay. 1983. Collagen formation by the hepatocyte in primary culture and in vivo. Science (Wash. DC). 219:1343-1345.

11. Albrechtsen, R., U. M. Wewer, and S. S. Thorgeirsson. 1988. De novo deposition of laminin-positive basement membrane in vitro by normal hepatocytes and during hepatocarcinogenesis. Hepatology. 8:538-546.

12. Chojkier, M., K. D. Lyche, and M. Filip. 1988. Increased production of collagen in vivo by hepatocytes and nonparenchymal cells in rats with carbon tetrachloride-induced hepatic fibrosis. Hepatology. 8:808-814.

13. Voss, B., J. Rauterberg, G. Pott, U. Brehmer, S. Allam, R. Lehmann, and D. B. Bassewitz. 1982. Nonparenchymal cells cultivated from explants of fibrotic liver resemble endothelial and smooth muscle cells from blood vessel walls. Hepatology. 2:19-28.

14. Irving, M. G., F. J. Roll, S. Huang, and M. Bissell. 1984. Characterization and culture of sinusoidal endothelium from normal rat liver: lipoprotein uptake and collagen phenotype. Gastroenterology. 87:1233-1247.

15. Pierce, R. A., M. R. Claug, R. S. Greco, J. Mackenzie, C. D. Boyd, and S. B. Deak. 1987. Increased procollagen mRNA levels in carbon tetrachloride-induced liver fibrosis in rats. J. Biol. Chem. 262:1652-1658.

16. Ala-Kokko, L., T. Pihlajaniemi, J. C. Meyers, K. I. Kivirikko, and E. R. Savolainen. 1987. Gene expression of type I, III, and IV collagens in hepatic fibrosis induced by dimethylnitrosamine in the rat. Biochem. J. 244:75-79.

17. Raghow, R., D. Gossage, J. M. Seyer, and A. H. Kang. 1984. Transcriptional regulation of type I collagen genes in cultured fibroblasts by a factor isolated from thioacetamide-induced fibrotic rat liver. J. Biol. Chem. 259:12718-12723.

18. Tsutsumi, M., A. Takada, and S. Takase. 1987. Characterization of Desmin-positive rat liver perisinusoidal cells. Hepatology. 7:277-284.

19. Genovese, C., D. Rowe, and Kream B. 1984. Construction of DNA sequences complementary to rat $\alpha 1$ and $\alpha 2$ collagen mRNA and their use in studying the regulation of type I collagen synthesis by 1,25-dihydroxyvitamin D. Biochemistry. 23:6210-6216.

20. Lian, G., Y. Yamada, and B. Crombrugghe. 1985. Coordinate regulation of the levels of type III and type I collagen mRNA in most but not all mouse fibroblast. J. Biol. Chem. 260:531-536.

21. Oberbaumer, I., M. Laurent, U. Schwarz, Y. Sakurai, Y. Yamada, G. Vogeli, T. Voss, B. Siebold, R. W. Glanville, and K. Kuhn. 1985. Amino acid sequence of the non-collagenous globular domain (NCI) of the $\alpha$ (IV) chain of basement membrane collagen as derived from complementary DNA. Eur. J. Biochem. 147:217-224.

22. Braun, L., J. E. Mead, M. Panzica, R. Mikumo, G. I. Bell and N. Fausto. 1988. Transforming growth factor- $\beta$ mRNA increases during liver regeneration: A possible paracrine mechanism of growth regulation. Proc. Natl. Acad. Sci. USA. 85:1539-1543.

23. Fort, P. H., L. Marty, M. Piechaczyk, S. E. Sabrouty, C. Danic, P. Jeanteur, and J. M. Blanchard. 1985. Various rat adult tissues express only one major mRNA species from the glyceraldehyde-3-phosphate-dehydrogenase multigenic family. Nucleic Acids Res. 13:14311442.

24. Cox, K. H., D. V. DeLeon, L. M. Angerer, and R. C. Angerer. 1984. Detection of mRNAs in sea urchin embryos by in situ hybridization using asymmetric RNA probes. Dev. Biol. 101:485-502.

25. Schweizer, J., and K. Goerttler. 1980. Synthesis in vitro of keratin polypeptides directed by mRNA isolated from newborn and adult mouse epidermis. Eur. J. Biochem. 112:243-249.

26. Aviv, H., and P. Leder. 1972. Purification of biologically active globin messenger RNA by chromatography on oligothymidylic acidcellulose. Proc. Natl. Acad. Sci. USA. 69:1408-1412.

27. Rav, N., R. Crkvenjakov, and H. Boedtker. 1979. Identification of procollagen mRNAs transformed to diazobenzyloxymethyl paper from formaldehyde agarose gels. Nucleic Acids Res. 6:3559-3567.

28. Evarts, R. P., P. Nagy, E. Marsden, and S. S. Thorgeirsson. 1987. In situ hybridization studies on expression of albumin and $\alpha$-fetoprotein during the early stage of neoplastic transformation in rat liver. Cancer Res. 47:5469-5475.

29. Clement, B., J. A. Grimaud, J. P. Campion, Y. Deugnier, and A. Guillouzo. 1986. Cell types involved in collagen and fibronectin production in normal and fibrotic human liver. Hepatology. 6:225234.

30. Bianci, F. D., G. Biagini, G. Ballardini, G. Cenacchi, A. Faccani, E. Pisi, R. Laschi, L. Liotta, and S. Garbisa. 1984. Basement 
membrane production by hepatocytes in chronic liver disease. Hepatology. 4:1167-1172.

31. Martinez-Hernandez, A. 1985. The hepatic extracellular matrix. II. Electron immunohistochemical studies in rats with $\mathrm{CCl}_{4}$-induced cirrhosis. Lab. Invest. 53:166-186.

32. Milani, S., H. Herbst, D. Schuppan, E. G. Hahn, and H. Stein. 1989. In situ hybridization for procollagen types I, III and IV mRNA in normal and fibrotic rat liver: evidence for predominant expression in nonparenchymal liver cells. Hepatology. 10:84-92.

33. Milani, S., H. Herbst, D. Schuppan, K. Y. Kim, E. O. Riecken and H. Stein. 1990. Procollagen expression by nonparenchymal rat liver cells in experimental biliary fibrosis. Gastroenterology. 98:175184.

34. Wahl, S. M., D. A. Hunt, L. M. Wakefield, F. N. McCartney, L. M. Wahl, A. B. Roberts, and M. B. Sporn. 1987. Transforming growth factor type $\beta$ induces monocyte chemotaxis and growth factor production. Proc. Natl. Acad. Sci. USA. 84:5788-5792.

35. Roberts, A. B., M. B. Sporn, R. K. Assoian, J. M. Smith, N. S.
Roche, L. M. Wakefield, U. I. Heine, L. A. Liotta, V. Falanga, J. H. Kehrl, and A. Fauci. 1986. Transforming growth factor type $\beta$ : Rapid induction of fibrosis and angiogenesis in vivo and stimulation of collagen formation in vitro. Proc. Natl. Acad. Sci. USA. 83:4167-4171.

36. Varga, J., J. Rosenbloom, and S. A. Jimenez. 1987. Transforming growth factor $\beta$ causes a persistent increase in steady state amounts of type I and type III collagen and fibronectin mRNA in normal human dermal fibroblasts. Biochem. J. 247:597-604.

37. Fine, A., and R. H. Goldstein. 1987. The effect of transforming growth factor $\boldsymbol{\beta}$ on cell proliferation and collagen formation by lung fibroblasts. J. Biol. Chem. 262:3897-3902.

38. Penttinan, R. P., S. Kobayashi, and P. Bornstein. 1988. Transforming growth factor $\beta$ increases mRNA for matrix proteins both in the presence and in the absence of changes in mRNA stability. Proc. Natl. Acad. Sci. USA. 85:1105-1108.

39. Weiner, F. R., M. A. Gianbrone, S. Takahashi, G. Annoni, M. S. Czaja, and M. A. Zern. 1988. Modulators of Ito cell collagen synthesis. Hepatology. 8:1253. (Abstr.) 